\title{
Upper gastrointestinal endoscopy for hematemesis in a patient aged 117 years
}

Gastrointestinal bleeding is the most important emergency in gastroenterology [1]. The number of people surviving to advanced age is increasing and more than $1 \%$ of the population aged 80 years or older are hospitalized each year for gastrointestinal bleeding [2]. We report a case of an Algerian man born in 1893 ( Fig. 1) who was admitted to our hospital with hematemesis.

On admission the patient's skin and mucosae were pale; his blood pressure was $90 / 60 \mathrm{mmHg}$ with a heart rate of 105 beats per minute and a regular rhythm. Abdominal examination revealed slight tenderness in the epigastrium and digital rectal examination found hard stools with no fresh blood or melena. His complete blood count showed normocytic anemia with hemoglobin at $6.8 \mathrm{~g} / \mathrm{dL}$ and a red cell count of $1.87 \times 10^{12} / \mathrm{L}$. Therapy with intravenous fluids, proton pump inhibitors, and blood transfusion was initiated. Upper gastrointestinal endoscopy was performed without general anesthesia using a 9.8-mm fiber gastroscope (Olympus, Tokyo, Japan). The procedure, which lasted approximately 8 minutes, found pale stomach mucosa with traces of blood in the stomach and erosions.

Pathological examination of mucosal specimens demonstrated mild Helicobacter pylori-related gastroduodenitis. $H$. pylori eradication therapy was initiated.

Centenarians are people who live to or beyond 100 years. Supercentenarians are people who have lived to the age of 110 or more and represent about one-thousandth of centenarians [3]. In 2009 the United Nations estimated that there were 455000 centenarians worldwide [4]. Our patient was born in 1893 in El Oued, Algeria. The patient was contacted by our department 1 year after the procedure, in February 2012. He was found to be in good shape and is now 119 years old.

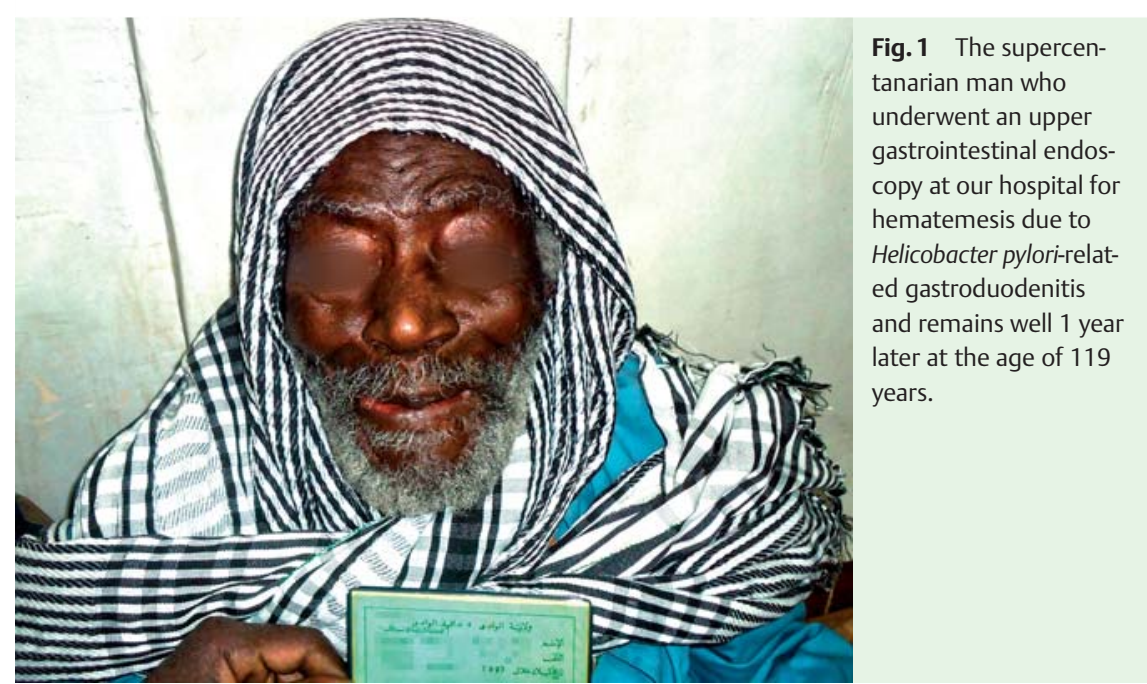

Endoscopy_UCTN_Code_CCL_1AB_2AZ_3AZ

References

1 Marek TA. Gastrointestinal bleeding. Endoscopy 2011; 43: 971 - 977

2 Kaplan RC, Heckbert SR, Koepsell TD et al. Risk factors for hospitalized gastrointestinal bleeding among older persons. Cardiovascular Health Study Investigators. J Am Geriatr Soc 2001; 49: 126-133

3 Oxford Dictionary of English. Oxford: Oxford University Press; 2010

4 United Nations Department of Economic and Social Affairs, Population Division. World Population Ageing 2009. New York: United Nations; 2010; 27

\section{Bibliography}

Dol http://dx.doi.org/

10.1055/s-0032-1309859

Endoscopy 2012; 44: E333

(c) Georg Thieme Verlag KG

Stuttgart · New York

ISSN 0013-726X

Corresponding author

N. Drid, MD

Department of Internal Medicine

General Hospital of El-Oued

El-Oued

Algeria

Fax: +213-32-210863

naimdrid.md@gmail.com 